\title{
Characterization of 3-dimensional papillary muscle displacement in in vivo ovine models of ischemic/functional mitral regurgitation
}

\author{
Wolfgang Bothe, MD, ${ }^{\mathrm{a}, \mathrm{b}}$ Tomasz A. Timek, MD, ${ }^{\mathrm{b}, \mathrm{c}}$ Frederick A. Tibayan, MD, ${ }^{\mathrm{b}, \mathrm{d}}$ Mario Walther, PhD,
} George T. Daughters, MS, ${ }^{b}$ Neil B. Ingels, Jr, PhD, ${ }^{\text {b,f }}$ and D. Craig Miller, MD

\section{ABSTRACT}

Objective: Papillary muscle (PM) displacement contributes to ischemic/ functional mitral regurgitation (IMR/FMR). The displaced PMs pull the mitral leaflets into the left ventricle (ie, toward the apex) thus hampering leaflet coaptation. Intuitively apical leaflet tethering results from apical PM displacement. The 3-dimensional directions of PM displacement are, however, incompletely characterized.

Methods: Data from in vivo ovine models of IMR (6-8 weeks of posterolateral infarction, $\mathrm{n}=12$ ) and FMR (9-21 days of rapid left ventricular pacing, $\mathrm{n}=11$ ) were analyzed. All sheep had radiopaque markers implanted on the anterior and posterior PM (PPM) tips, around the mitral annulus, and on the left ventricular apex. To explore 3-dimensional PM displacement directions, differences in marker coordinates were calculated at end-systole before and during IMR/FMR using a right-handed coordinate system centered on the mitral annular "saddle horn" with the y-axis passing through the apical marker.

Results: No apical PM displacement was observed during either IMR or FMR. The anterior PM displaced laterally during FMR. Posterolateral PPM displacement was observed during IMR and FMR.

Conclusions: Experimental in vivo ovine models suggest posterolateral PPM displacement as a predominant pathomechanism leading to apical leaflet tethering during IMR/FMR. (J Thorac Cardiovasc Surg 2019;157:1444-9)

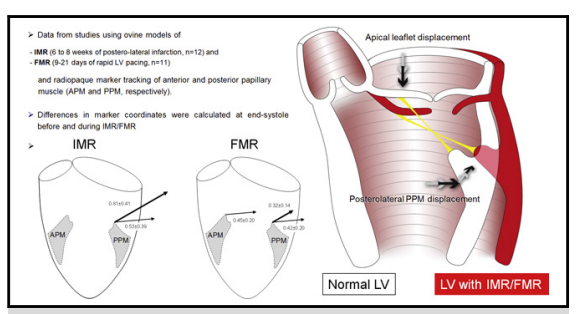

Data from experimental ovine studies suggest that apical anterior mitral leaflet tethering is associated with posterolateral papillary muscle dislocation in ischemic/functional mitral regurgitation.

\section{Central Message}

Consistent posterolateral, but not apical, dislocation of the posterior papillary muscle was observed with experimental IMR/FMR.

\section{Perspective}

PM displacement contributes to apical leaflet tethering during IMR/FMR. In these experimental ovine IMR/FMR studies consistent posterolateral, but not apical, displacement of the posterior PM was observed.

See Commentary on page 1450 .
From the a Department of Cardiovascular Surgery, Heart Center Freiburg-Bad Krozingen, Faculty of Medicine, University of Freiburg, Freiburg, Germany; ${ }^{\mathrm{b}}$ Department of Cardiothoracic Surgery, Stanford University School of Medicine, Stanford, Calif; ' Division of Cardiothoracic Surgery Spectrum Health, Grand Rapids, Mich; ${ }^{\mathrm{d}}$ Department of Cardiothoracic Surgery, Oregon Health and Science University, Portland, Ore; ${ }^{\mathrm{e}}$ Department of Mathematics and Applied Statistics, University of Applied Sciences, Jena, Germany; and ${ }^{\mathrm{f}}$ Laboratory of Cardiovascular Physiology and Biophysics, Research Institute of the Palo Alto Medical Foundation, Palo Alto, Calif.

D. Craig Miller received R01 research grants, National Heart, Lung, and Blood Institute, National Institutes of Health HL29589 (1982-2008), and HL67025 (20012010).

Received for publication April 12, 2018; revisions received Sept 11, 2018; accepted for publication Sept 18, 2018; available ahead of print Nov 14, 2018.

Address for reprints: D. Craig Miller, MD, Department of Cardiothoracic Surgery, Falk Cardiovascular Research Center, Stanford University School of Medicine, Stanford, CA 94305-5407 (E-mail: dcm@stanford.edu).

$0022-5223 / \$ 36.00$

Copyright $($ c 2018 by The American Association for Thoracic Surgery

https://doi.org/10.1016/j.jtcvs.2018.09.069
In patients with ischemic/functional mitral regurgitation (IMR/FMR) mitral valve replacement is increasingly advocated as a surgical treatment standard ${ }^{1}$ because of suboptimal results with reductive ring annuloplasty. ${ }^{2,3}$ Poor repair outcomes are thought to be related to ongoing left ventricle (LV) remodeling and papillary muscle (PM) displacement leading to recurrent leaflet tethering. ${ }^{4}$ Nevertheless, lasting mitral repair might be superior to valve replacement, ${ }^{5}$ and surgical strategies that specifically aim

$\checkmark$ Scanning this $\mathrm{QR}$ code will take you to the article title page to access supplementary information. 


\section{Abbreviations and Acronyms \\ $\mathrm{APM} / \mathrm{PPM}=$ anterior/posterior papillary muscle \\ $\mathrm{IMR} / \mathrm{FMR}=$ ischemic/functional mitral regurgitation \\ $\mathrm{LV} \quad=$ left ventricle \\ PM = papillary muscle}

to address subvalvular distortions of PM geometry have been introduced clinically to improve repair durability. ${ }^{6-13}$ However, because of incomplete understanding of the alterations of subvalvular geometry associated with IMR/ FMR, no current consensus exists regarding optimal subvalvular repair. Mitral leaflet tethering has been shown to be associated with clinical and experimental IMR/ FMR, ${ }^{14,15}$ and apical PM displacement has been intuitively assumed to be the putative mechanism. The precise PM displacement in patients with IMR/FMR is, however, difficult to determine because clinical imaging modalities are unable to accurately track distinct anatomic landmarks over time. Experimental studies using radiopaque markers or sonomicrometry crystals have failed to show apical posterior PM (PPM) displacement ${ }^{16-19}$ during IMR. To characterize 3-dimensional perturbations of PM geometry associated with IMR/FMR, we analyzed data from in vivo ovine studies using radiopaque marker tracking of the anterior PM (APM) and PPM during experimental IMR and FMR.

\section{METHODS}

Data from 2 experimental ovine studies performed by our research group were analyzed to investigate 3-D vectors of APM and PPM displacement. These data have been partially published. ${ }^{20-22}$ All animal protocols were approved by the Stanford Medical Center Laboratory Research Animal Review committee and conducted according to Stanford University policy. All studies included radiopaque marker placement on APM and PPM tips and around the mitral annulus using cardiopulmonary bypass and cardioplegic arrest. In the study investigating the effects of IMR, baseline data from 12 sheep were acquired 6 to 8 days after surgical placement of radiopaque markers (control). Experimental IMR data were acquired 6 to 8 weeks after induction of a posterolateral infarct (snare occlusion of obtuse marginal branches; see Tibayan and colleagues, ${ }^{21}$ for details). In the model of experimental FMR, baseline data from 11 sheep were acquired 5 to 8 days after surgical placement of radiopaque markers (control). A rapid-pacing pulse generator (Prodigy S 8164; Medtronic Inc, Minneapolis, Minn) was inserted into a subcutaneous pocket and connected to the previously externalized LV electrode, and the animal was recovered. Rapid pacing was initiated 24 hours later. FMR data were obtained 9 to 21 days after rapid left ventricular pacing (180-230 beats per minute; see Timek and colleagues ${ }^{22}$ for details). All data acquisitions were performed using biplane video fluoroscopy $(60 \mathrm{~Hz})$ in standardized fashion, and marker positions from both views were digitized, merged, and analyzed using customized computer software. ${ }^{23}$ To assess the presence of apical PM displacement, the orthogonal distance from each PM marker to the least-squares mitral annular plane at end-systole was calculated before and during IMR or FMR.

To specify precise vectors of APM/PPM displacement, 3-D marker positions were determined at end-systole before and after induction of experimental IMR and FMR. A left-handed coordinate system was used with the lateral (y-) axis pointing toward the lateral mitral annular marker, the apical (x-) axis orthogonal to the $\mathrm{y}$-axis in a plane with the $\mathrm{LV}$ apex marker. The $\mathrm{z}$-axis was orthogonal to the $\mathrm{x}$-y plane pointing posteriorly (Figure 1,
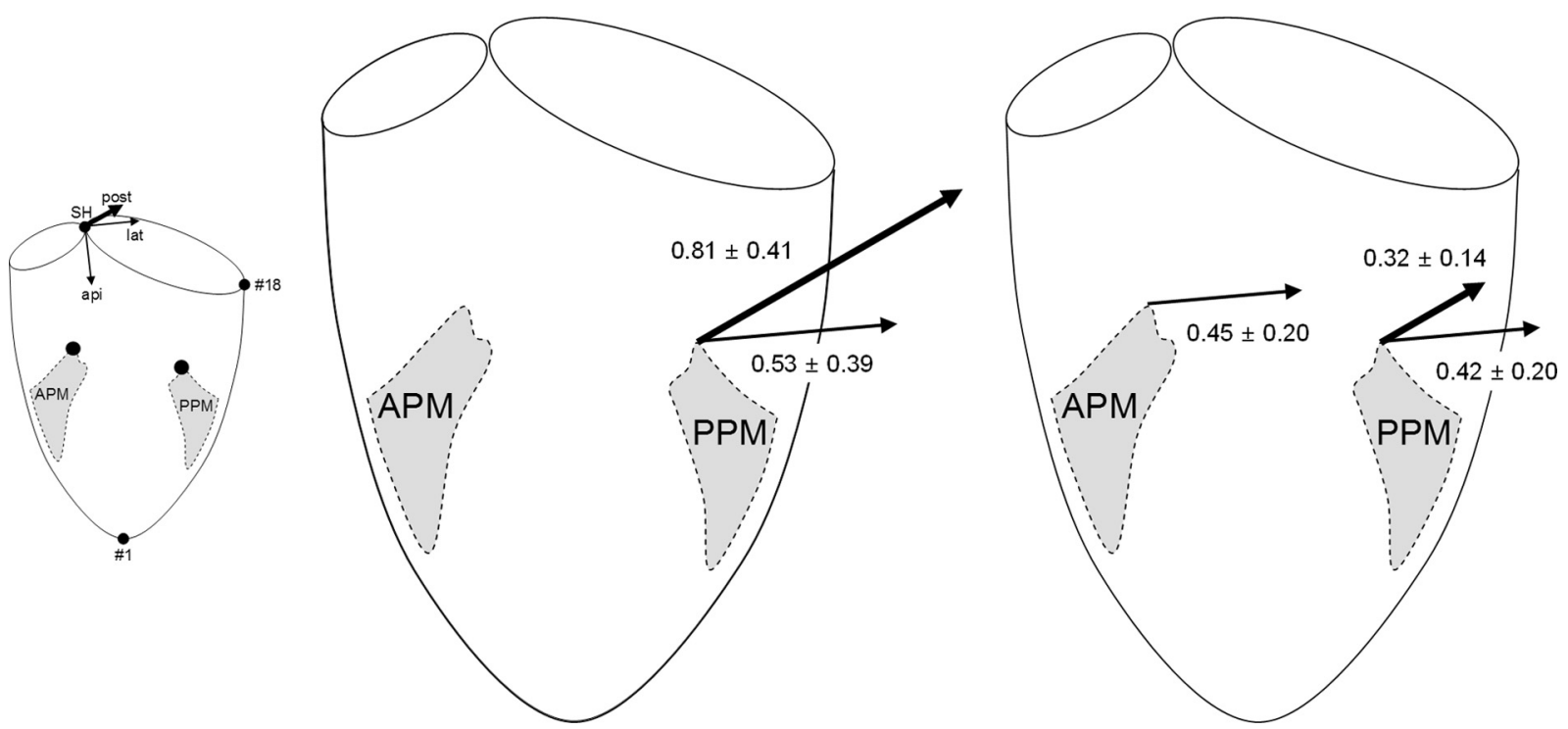

FIGURE 1. Schematic illustrations depicting 3-dimensional anterior $(A P M)$ and posterior papillary muscle ( $P P M)$ displacement vectors in experimental ovine models of ischemic $(I M R)$ and functional mitral regurgitation $(F M R)$. Arrows indicate vectors that reached statistical significance according to Table 2. Arrow lengths are proportionate to the average of the differences between control and the respective IMR/FMR values. Arrows in the small schematic illustrate the coordinate system used (see Methods). SH, Saddle horn; post, posterior; lat, lateral; api, apical; \#18, mid-lateral mitral annular marker; $\# 1$, left ventricular apex marker. 
TABLE 1. Hemodynamics

\begin{tabular}{|c|c|c|c|c|c|c|}
\hline & Control & IMR & $P$ value & Control & FMR & $P$ value \\
\hline MR $(0-4+)$ & $0.6 \pm 0.5$ & $2.5 \pm 0.6$ & $<.001 *$ & $0.2 \pm 0.3$ & $2.2 \pm 0.9$ & $<.001 *$ \\
\hline $\mathrm{LV} \mathrm{dP/dt} \max , \mathrm{mm} \mathrm{Hg} / \mathrm{s}$ & $1979 \pm 785$ & $1256 \pm 506$ & $.002 *$ & $1350 \pm 219$ & $1162 \pm 374$ & .290 \\
\hline $\mathrm{EDV}, \mathrm{mL} / \mathrm{m}^{2}$ & $128 \pm 36$ & $180 \pm 40$ & $<.001 *$ & $160 \pm 57$ & $201 \pm 67$ & $.001 *$ \\
\hline
\end{tabular}

Values are mean \pm standard deviation. $I M R$, Ischemic mitral regurgitation; $F M R$, functional mitral regurgitation; $M R$, mitral regurgitation; $L V$, left ventricle; $d P / d t_{\text {max }}$, maximum of first derivative of pressure versus time; $E D V$, end-diastolic volume. *Statistically significant after Holm-Bonferroni adjustment.

small schematic). Displacement vectors were calculated as differences of $\mathrm{x}, \mathrm{y}$, and $\mathrm{z}$ coordinates between baseline and respective experimental state.

Data were compared using Student $t$ test for paired samples. The Bonferroni adjustment was applied to account for the different measurement conditions ( 3 coordinate axes, distance to mitral annular plane) within the 2 different PMs (overall significance level set to $P \leq .05$; Bonferroni corrected level of significance was set to $P<.006$ ). All results are presented with mean and standard deviation. Statistical analysis was performed using SPSS 21 for Windows (IBM Corp, Armonk, NY).

\section{RESULTS}

Both animal subgroups (experimental IMR and FMR) developed significant mitral regurgitation and signs of LV failure as indicated by an increase in left-ventricular enddiastolic volume (Table 1). Table 2 shows the distances of APM and PPM to the mitral annular plane before and during IMR and FMR. During both experimental conditions (IMR and FMR), none of the changes in distances of either APM or PPM to the mitral annular plane was statistically significant, but a trend toward a decrease of the PPM distance to the mitral annular plane during IMR and FMR was observed $(3.82 \pm 0.53$ vs $3.16 \pm 0.41, P=.014$ and $3.01 \pm 0.80$ vs $2.69 \pm 0.67, P=.026$, respectively). Table 3 shows the APM and PPM positions before and during IMR and FMR. The APM did not displace significantly during experimental IMR and laterally during FMR (lateral: $0.97 \pm 0.47$ vs $1.43 \pm 0.43, P<.001)$. The PPM displaced posterolaterally during IMR (posterior: $0.58 \pm 0.40$ vs $1.39 \pm 0.46$, $P<.001$, lateral: $0.66 \pm 0.55$ vs $1.19 \pm 0.70, P=.001$ ) and FMR (posterior: $0.10 \pm 0.46$ vs $0.22 \pm 0.48$, $P<.001$, lateral: $0.74 \pm 0.48$ vs $1.16 \pm 0.45, P<.001$ ). Figure 1 shows APM and PPM displacement vectors that reached statistical significance.

\section{DISCUSSION}

The main findings of this experimental work are shown in both the Graphical Abstract and in Video 1. During experimental IMR and FMR: (1) no apical PM displacement was observed; (2) the displacement vector of the PPM was directed posterolaterally. These findings suggest posterolateral PPM displacement as predominant pathomechanism leading to apical leaflet tethering during IMR/FMR.

Surgical mitral valve repair in patients with IMR/FMR using a ring annuloplasty alone is associated with high rates of residual/recurrent mitral regurgitation ${ }^{2}$ because prosthetic ring implantation might enhance leaflet tethering while ongoing left ventricular dilatation leads to further $\mathrm{PM}$ displacement and recurrent mitral regurgitation. ${ }^{24} \mathrm{As}$ a consequence, several authors have introduced adjunctive subvalvular techniques (in addition to annuloplasty) to counteract PM displacement. ${ }^{6-9,25}$

In the clinical literature, PM displacements have frequently been associated with an apically directed vector. ${ }^{26-30}$ On the basis of increases in echocardiographically measured tethering lengths of APM and PPM in patients with FMR, Yiu and colleagues concluded that apical displacement of PMs is a major determinant of valvular tenting. ${ }^{29}$ Numerous other clinical studies have used tethering lengths to characterize 3-D changes of the subvalvular apparatus in patients with FMR/IMR. ${ }^{24,29,31-35}$ Tethering length, however, is a 2-dimensional parameter and does not allow drawing conclusions about the 3-D vectors of PM displacement.

Several experimental studies exist that report 3-D alterations of the geometry of the PMs during IMR. Gorman and colleagues showed a decrease in the distance between the PPM and the posterior commissure in an ovine model of IMR, ${ }^{17}$ which suggests a lack of apical PPM displacement and is in accordance with our findings. Similar geometric perturbation of PPM geometry were reported by Lai and colleagues during acute ovine IMR. ${ }^{36}$ Myocardial marker tagging of multiheaded papillary tips also failed to show apical displacement of any PM heads during acute ovine IMR. ${ }^{19}$ The data from these acute studies show similar trends compared with our model of longer-term

TABLE 2. Distances of APM and PPM to the MA plane before and during IMR and FMR

\begin{tabular}{lcccccc}
\hline Distance to MA plane & Control, cm & IMR, cm & $\boldsymbol{P}$ value & Control, cm & FMR, cm & $\boldsymbol{P}$ value \\
\hline APM & $3.81 \pm 0.70$ & $3.70 \pm 0.39$ & .627 & $2.50 \pm 0.85$ & $2.52 \pm 0.79$ & .867 \\
PPM & $3.82 \pm 0.53$ & $3.16 \pm 0.41$ & .014 & $3.01 \pm 0.80$ & $2.69 \pm 0.67$ & .026 \\
\hline
\end{tabular}

Values are mean \pm standard deviation at end-systole. $M A$, Mitral annular; $I M R$, ischemic mitral regurgitation; $F M R$, functional mitral regurgitation; $A P M$, anterior papillary muscle; $P P M$, posterior papillary muscle. 
TABLE 3. APM and PPM positions at end-systole before and during IMR and FMR

\begin{tabular}{|c|c|c|c|c|c|c|}
\hline & Control & IMR & $P$ value & Control & FMR & $P$ value \\
\hline \multicolumn{7}{|c|}{ APM position } \\
\hline Lateral & $1.30 \pm 0.85$ & $1.69 \pm 0.98$ & .498 & $0.97 \pm 0.47$ & $1.43 \pm 0.43$ & $<.001 *$ \\
\hline Posterior & $-2.05 \pm 0.72$ & $-2.18 \pm 0.54$ & .488 & $-2.15 \pm 0.28$ & $-2.62 \pm 0.54$ & .009 \\
\hline Apical & $5.06 \pm 1.02$ & $4.79 \pm 0.86$ & .029 & $3.05 \pm 0.55$ & $3.01 \pm 0.62$ & .743 \\
\hline \multicolumn{7}{|c|}{ PPM position } \\
\hline Lateral & $0.66 \pm 0.55$ & $1.19 \pm 0.70$ & $.001 *$ & $0.74 \pm 0.48$ & $1.16 \pm 0.45$ & $<.001 *$ \\
\hline Posterior & $0.58 \pm 0.40$ & $1.39 \pm 0.46$ & $<.001 *$ & $-0.10 \pm 0.46$ & $0.22 \pm 0.48$ & $<.001 *$ \\
\hline Apical & $5.40 \pm 1.04$ & $4.94 \pm 0.59$ & .282 & $4.11 \pm 0.67$ & $4.46 \pm 1.01$ & .153 \\
\hline
\end{tabular}

Values are in $\mathrm{cm}$, mean \pm standard deviation, and describe PM positions at end-systole (see Methods for coordinate system used). Negative values represent a PM position in the opposite direction as indicated (ie, septal, anterior and toward the LV base as opposed to lateral, posterior, and apical, respectively). IMR, Ischemic mitral regurgitation; FMR, functional mitral regurgitation; $A P M$, anterior papillary muscle; $P P M$, posterior papillary muscle. *Statistically significant after Holm-Bonferroni adjustment.

IMR/FMR. Interestingly, in our IMR/FMR models the PPM distance to the mitral annular plane during IMR and FMR tended to decrease $(3.82 \pm 0.53$ vs $3.16 \pm 0.41, P=.014$ and $3.01 \pm 0.80$ vs $2.69 \pm 0.67, P=.026$, respectively). This trend might have become significant with a bigger sample size and suggests that apical leaflet tethering might occur even if the PMs move closer to the annular plane.

Our finding of posterolateral, but not apical, displacement of the PPM during IMR/FMR is also indirectly supported by other reports. Balloon repositioning of the displaced PPM in ovine IMR purely in the anteroseptal direction decreased leaflet tethering and reduced mitral insufficiency. ${ }^{25,37}$ The Coapsys device (Myocor Inc, Maple Grove, Minn), which primarily repositions the PPM toward the LV septum, has shown a clinically similar effect. ${ }^{38}$ On the contrary, pulling the PPM toward the posterior commissure (which includes a vector mainly directed toward the LV base) during acute ovine IMR did not ameliorate mitral regurgitation $^{39}$ whereas PPM relocation toward the right fibrous trigone (which includes a septal and anterior vector) in addition to reductive annuloplasty decreased leaflet tethering in a porcine model of IMR/FMR. ${ }^{40}$

A recent prospective, randomized trial in patients with severe IMR showed improved long-term cardiac outcomes in patients who underwent restrictive mitral annuloplasty and a PM sling compared with patients who received a restrictive annuloplasty alone. ${ }^{11}$ In this novel subvalvular repair, PMs are approximated using a polytetrafluoroethylene tube with the relocation vector of the PPM primarily directed anteriorly and toward the septum, but not toward the LV base.

\section{Clinical Inference}

For a meaningful discussion of clinical inference the limitations of our data (see Study Limitations) including potential differences to patients with long-lasting IMR/FMR must be considered. An important goal of this work is therefore to stimulate further clinical research investigating 3-D PM displacement vectors during IMR/FMR. Because mitral
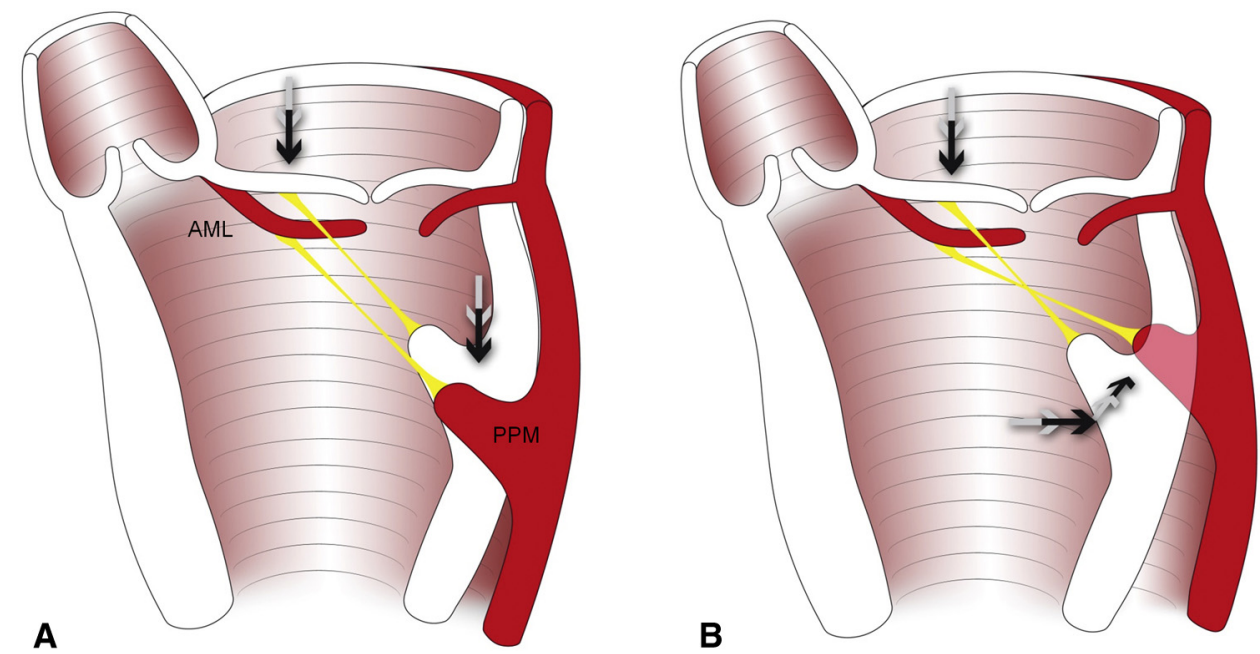

FIGURE 2. Schematic illustrating the hypothesized predominant mechanism leading to leaflet tethering during ischemic and functional mitral regurgitation: apical leaflet displacement is not—as frequently hypothesized—associated with apical (A), but with a posterolateral displacement of the posteromedial papillary muscle (PPM; B). AML, Anterior mitral leaflet. 


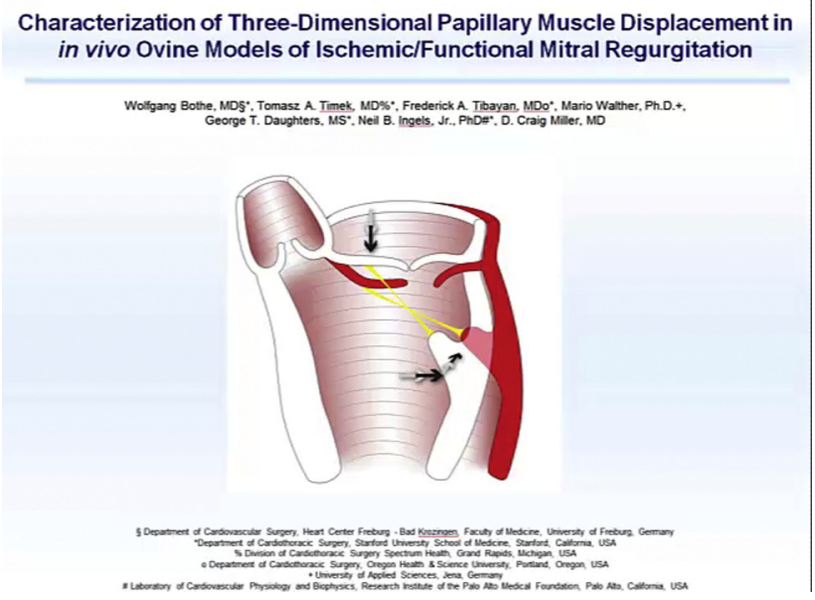

VIDEO 1. Presentation illustrating the key findings of this study. Video available at: https://www.jtcvs.org/article/S0022-5223(18)32577-7/fulltext.

leaflets are often observed to be tethered apically in IMR/ FMR, it is frequently assumed that apical leaflet tethering results from apical PPM displacement (Figure 2, A). Our analysis of 2 different in vivo animal data sets from our laboratory, however, revealed that mitral leaflet tethering in experimental ovine in vivo models does not result from apical, but from posterolateral PPM dislocation (Figure 1, B). In case these findings translate to patients with IMR/FMR these data suggest that subvalvular surgical or interventional approaches to IMR/FMR should focus on relocating the PPM anteriorly and toward the septum.

\section{Study Limitations}

The results of the presented data must be viewed in the context of several limitations. First, left ventricular alterations in these experimental models of IMR/FMR significantly differ from patients with long-term IMR/FMR. Apical PM displacement could occur in IMR/FMR patients even secondary to posterolateral PPM displacement. Clinical studies assessing 3-D changes of the PM geometry in IMR/ FMR patients over a longer time period are needed to resolve this issue. Second, our analyses focus solely on 3-D changes in the PM geometry and no additional hemodynamic data or data from alterations in the LV or leaflet geometry were calculated. These data have, however, been published earlier and have been shown to be consistent with typical alterations observed during experimental IMR or FMR. ${ }^{20,22,41}$ Third, species differences in PM blood supply might limit the extrapolation of these results to patients ${ }^{42}$ and mitral valve anatomy might be heterogeneous between patients. ${ }^{43}$ Fourth, we investigated only 1 time point in the cardiac cycle (endsystole). Our analyses therefore do not provide insight into cases in which FMR/IMR arises because of dynamic PM dysfunction. ${ }^{44}$ Last, recently published algorithms for the surgical treatment of IMR/FMR suggest the additional use of subvalvular repair on the basis of LV wall perfusion or motion abnormalities. ${ }^{45}$ In our study, no analysis of LV motion was performed, and it is possible that PM displacement vectors differ in individual patients. However, it is reasonable to assume that the observed alterations of PM geometry in our study apply to most patients with IMR/FMR.

\section{CONCLUSIONS}

IMR/FMR is associated with apical leaflet tethering and PM displacement. These experimental in vivo ovine models suggest posterolateral PPM but not apical PM displacement as a predominant pathomechanism leading to leaflet tethering during IMR/FMR.

\section{Conflict of Interest Statement}

D. Craig Miller is a consultant, Medtronic CardioVascular Division. All other authors have nothing to disclose with regard to commercial support.

We acknowledge the superb technical assistance provided by Carol W. Mead, BA, and Maggie Brophy, RVT.

\section{References}

1. Salmasi MY, Acharya M, Humayun N, Baskaran D, Hubbard S, Vohra H. Is valve repair preferable to valve replacement in ischaemic mitral regurgitation? A systematic review and meta-analysis. Eur J Cardiothorac Surg. 2016;50:17-28.

2. Goldstein D, Moskowitz AJ, Gelijns AC, Ailawadi G, Parides MK, Perrault LP, et al. Two-year outcomes of surgical treatment of severe ischemic mitral regurgitation. N Engl J Med. 2016;374:344-53.

3. Michler RE, Smith PK, Parides MK, Ailawadi G, Thourani V, Moskowitz AJ, et al. Two-year outcomes of surgical treatment of moderate ischemic mitral regurgitation. N Engl J Med. 2016;374:1932-41.

4. Kainuma S, Funatsu T, Kondoh H, Yokota T, Maeda S, Shudo Y, et al. Beneficial effects of restrictive annuloplasty on subvalvular geometry in patients with functional mitral regurgitation and advanced cardiomyopathy. J Thorac Cardiovasc Surg. 2018;156:630-8.e1.

5. Bolling SF. How do we ensure a "good" repair in ischemic mitral regurgitation? J Am Coll Cardiol. 2016;67:2347-8.

6. Kron IL, Green GR, Cope JT. Surgical relocation of the posterior papillary muscle in chronic ischemic mitral regurgitation. Ann Thorac Surg. 2002;74:600-1.

7. Bothe W, Doenst T. Ring-noose-string technique allows adjustable papillary muscle repositioning during minimally invasive mitral valve repair in patients with functional/ischemic mitral regurgitation. Thorac Cardiovasc Surg. 2016; 64:447-9.

8. Langer F, Groesdonk HV, Kunihara T, Schäfers HJ. Dynamic RING + STRING for ischemic mitral regurgitation: papillary muscle repositioning and modification of the septal-lateral diameter in the loaded beating heart under echocardiographic guidance. J Thorac Cardiovasc Surg. 2011;141:1315-6.

9. Ueno T, Sakata R, Iguro Y, Nagata T, Otsuji Y, Tei C. New surgical approach to reduce tethering in ischemic mitral regurgitation by relocation of separate heads of the posterior papillary muscle. Ann Thorac Surg. 2006;81:2324-5.

10. Mihos CG, Larrauri-Reyes M, Santana O. A meta-analysis of ring annuloplasty versus combined ring annuloplasty and subvalvular repair for moderate-to-severe functional mitral regurgitation. J Card Surg. 2016;31:31-7.

11. Nappi F, Lusini M, Spadaccio C, Nenna A, Covino E, Acar C, et al. Papillary muscle approximation versus restrictive annuloplasty alone for severe ischemic mitral regurgitation. J Am Coll Cardiol. 2016;67:2334-46.

12. Mihos CG, Yucel E, Santana O. The role of papillary muscle approximation in mitral valve repair for the treatment of secondary mitral regurgitation. Eur J Cardiothorac Surg. 2017;51:1023-30.

13. Nappi F, Spadaccio C, Nenna A, Lusini M, Fraldi M, Acar C, et al. Is subvalvular repair worthwhile in severe ischemic mitral regurgitation? Subanalysis of the papillary muscle approximation trial. J Thorac Cardiovasc Surg. 2017;153: 286-95.e2. 
14. Bothe W, Kvitting JP, Stephens EH, Swanson JC, Liang DH, Ingels NB, et al. Effects of different annuloplasty ring types on mitral leaflet tenting area during acute myocardial ischemia. J Thorac Cardiovasc Surg. 2011;141:345-53.

15. Golba K, Mokrzycki K, Drozdz J, Cherniavsky A, Wrobel K, Roberts BJ, et al. Mechanisms of functional mitral regurgitation in ischemic cardiomyopathy determined by transesophageal echocardiography (from the surgical treatment for ischemic heart failure trial). Am J Cardiol. 2013;112:1812-8.

16. Komeda M, Glasson JR, Bolger AF, Daughters GT, MacIsaac A, Oesterle SN, et al. Geometric determinants of ischemic mitral regurgitation. Circulation. 1997;96(9 Suppl):II128-33.

17. Gorman JH, Gorman RC, Jackson BM, Enomoto Y, St John-Sutton MG, Edmunds LH. Annuloplasty ring selection for chronic ischemic mitral regurgitation: lessons from the ovine model. Ann Thorac Surg. 2003;76:1556-63.

18. Lai DT, Timek TA, Dagum P, Green GR, Glasson JR, Daughters GT, et al. The effects of ring annuloplasty on mitral leaflet geometry during acute left ventricular ischemia. J Thorac Cardiovasc Surg. 2000;120:966-75.

19. Timek TA, Lai DT, Bothe W, Liang D, Daughters GT, Ingels NB, et al. Geometric perturbations in multiheaded papillary tip positions associated with acute ovine ischemic mitral regurgitation. J Thorac Cardiovasc Surg. 2015;150:232-7.

20. Timek TA, Lai DT, Tibayan F, Liang D, Daughters GT, Dagum P, et al. Ischemia in three left ventricular regions: insights into the pathogenesis of acute ischemic mitral regurgitation. J Thorac Cardiovasc Surg. 2003;125:559-69.

21. Tibayan FA, Rodriguez F, Zasio MK, Bailey L, Liang D, Daughters GT, et al. Geometric distortions of the mitral valvular-ventricular complex in chronic ischemic mitral regurgitation. Circulation. 2003;108(Suppl 1):II116-21.

22. Timek TA, Dagum P, Lai DT, Liang D, Daughters GT, Ingels NB, et al. Pathogenesis of mitral regurgitation in tachycardia-induced cardiomyopathy. Circulation. 2001;104(12 Suppl 1):I47-53.

23. Niczyporuk MA, Miller DC. Automatic tracking and digitization of multiple radiopaque myocardial markers. Comput Biomed Res Int J. 1991;24:129-42.

24. Yu HY, Su MY, Chen YS, Lin FY, Tseng WY. Mitral tetrahedron as a geometrical surrogate for chronic ischemic mitral regurgitation. Am J Physiol Heart Circ Physiol. 2005;289:H1218-25.

25. Hung J, Solis J, Guerrero JL, Braithwaite GJC, Muratoglu OK, Chaput M, et al. A novel approach for reducing ischemic mitral regurgitation by injection of a polymer to reverse remodel and reposition displaced papillary muscles. Circulation. 2008;118(14 Suppl):S263-9.

26. Lee AP, Acker M, Kubo SH, Bolling SF, Park SW, Bruce CJ, et al. Mechanisms of recurrent functional mitral regurgitation after mitral valve repair in nonischemic dilated cardiomyopathy: importance of distal anterior leaflet tethering. Circulation. 2009;119:2606-14.

27. Dal-Bianco JP, Aikawa E, Bischoff J, Guerrero JL, Handschumacher MD, Sullivan S, et al. Active adaptation of the tethered mitral valve: insights into a compensatory mechanism for functional mitral regurgitation. Circulation. 2009;120:334-42.

28. Agricola E, Oppizzi M, Pisani M, Meris A, Maisano F, Margonato A. Ischemic mitral regurgitation: mechanisms and echocardiographic classification. Eur $J$ Echocardiogr. 2008;9:207-21.

29. Yiu SF, Enriquez-Sarano M, Tribouilloy C, Seward JB, Tajik AJ. Determinants of the degree of functional mitral regurgitation in patients with systolic left ventricular dysfunction: a quantitative clinical study. Circulation. 2000;102:1400-6.

30. Levine RA, Hagége AA, Judge DP, Padala M, Dal-Bianco JP, Aikawa E, et al. Mitral valve disease-morphology and mechanisms. Nat Rev Cardiol. 2015;12: 689-710.

31. Uemura T, Otsuji Y, Nakashiki K, Yoshifuku S, Maki Y, Yu B, et al. Papillary muscle dysfunction attenuates ischemic mitral regurgitation in patients with localized basal inferior left ventricular remodeling: insights from tissue Dopple strain imaging. J Am Coll Cardiol. 2005:46:113-9.

32. Kumanohoso T, Otsuji Y, Yoshifuku S, Matsukida K, Koriyama C, Kisanuki A, et al. Mechanism of higher incidence of ischemic mitral regurgitation in patients with inferior myocardial infarction: quantitative analysis of left ventricular and mitral valve geometry in 103 patients with prior myocardial infarction. $J$ Thorac Cardiovasc Surg. 2003;125:135-43.

33. Yu HY, Su MY, Liao TY, Peng HH, Lin FY, Tseng WY. Functional mitral regurgitation in chronic ischemic coronary artery disease: analysis of geometric alterations of mitral apparatus with magnetic resonance imaging. J Thorac Cardiovasc Surg. 2004;128:543-51.

34. D’Ancona G, Biondo D, Mamone G, Marrone G, Pirone F, Santise G, et al Ischemic mitral valve regurgitation in patients with depressed ventricular function: cardiac geometrical and myocardial perfusion evaluation with magnetic resonance imaging. Eur J Cardiothorac Surg. 2008:34:964-8.

35. Veronesi F, Corsi C, Sugeng L, Caiani EG, Weinert L, Mor-Avi V, et al. Quantification of mitral apparatus dynamics in functional and ischemic mitral regurgitation using real-time 3-dimensional echocardiography. J Am Soc Echocardiogr 2008;21:347-54.

36. Lai DT, Timek TA, Tibayan FA, Green GR, Daughters GT, Liang D, et al. The effects of mitral annuloplasty rings on mitral valve complex 3-D geometry during acute left ventricular ischemia. Eur J Cardiothorac Surg. 2002;22:808-16.

37. Hung J, Chaput M, Guerrero JL, Handschumacher MD, Papakostas L, Sullivan S, et al. Persistent reduction of ischemic mitral regurgitation by papillary muscle repositioning: structural stabilization of the papillary muscle-ventricular wall complex. Circulation. 2007;116(11 Suppl):I259-63.

38. Mishra YK, Mittal S, Jaguri P, Trehan N. Coapsys mitral annuloplasty for chronic functional ischemic mitral regurgitation: 1-year results. Ann Thorac Surg. 2006 $81: 42-6$.

39. Langer F, Rodriguez F, Ortiz S, Cheng A, Nguyen TC, Zasio MK, et al. Subvalvular repair: the key to repairing ischemic mitral regurgitation? Circulation. 2005; 112(9 Suppl):I383-9.

40. Jensen H, Jensen MO, Smerup MH, Vind-Kezunovic S, Ringgaard S Andersen NT, et al. Impact of papillary muscle relocation as adjunct procedure to mitral ring annuloplasty in functional ischemic mitral regurgitation. Circulation. 2009;120(11 Suppl):S92-8.

41. Tibayan FA, Rodriguez F, Langer F, Zasio MK, Bailey L, Liang D, et al. Annular or subvalvular approach to chronic ischemic mitral regurgitation? J Thorac Cardiovasc Surg. 2005;129:1266-75.

42. Walmsley R. Anatomy of human mitral valve in adult cadaver and comparative anatomy of the valve. Br Heart J. 1978;40:351-66.

43. Krawczyk-Ożóg A, Hołda MK, Bolechała F, Siudak Z, Sorysz D, Dudek D, et al Anatomy of the mitral subvalvular apparatus. J Thorac Cardiovasc Surg. 2018 155:2002-10.

44. Messas E, Guerrero JL, Handschumacher MD, Chow CM, Sullivan S, Schwammenthal E, et al. Paradoxic decrease in ischemic mitral regurgitation with papillary muscle dysfunction: insights from three-dimensional and contras echocardiography with strain rate measurement. Circulation. 2001;104:1952-7.

45. Hernandez-Vaquero D, Díaz R, Álvarez-Cabo R, Vigil-Escalera C, Silva J. Mitra valve repair for moderate ischemic mitral regurgitation. J Thorac Dis. 2016;8: $1410-3$.

Key Words: mitral valve, mitral regurgitation, mitral valve repair, cardiomyopathy, heart failure, pathophysiology, surgery techniques, cardiac intervention 